\title{
The Sixteenth Annual Meeting, 1987
}

The Sixteenth Annual Meeting of the College was held in Belfast on 30 June, 1 and 2 July 1987 under the Presidency of Dr Thomas Bewley and, following his inauguration, $\mathrm{Dr}$ J. L. T. Birley.

\section{SCIENTIFIC MeETINGS}

The Scientific Meetings were held in the Medical Biology Centre, Queen's University, Belfast.

\section{Business MeEting}

The Business Meeting was held on 1 July and was chaired by Dr J. L. T. Birley. It was attended by 70 Members of the College.

The minutes of the previous meeting held in Southampton on 9 July 1986 and published in the Bulletin, December 1986 were approved and signed.

The Report of the Registrar and the Annual Report were received and approved.

The Report of the Treasurer and the Annual Accounts for 1986 were received and approved.

The appointment of auditors and new subscription rates were approved.

The Resolution "To approve the formation of a Specialist Section to be called the Substance Misuse Section" (proposed by Dr M. Carney and seconded by Dr P. Mullin) was approved.

\section{REGISTRAR'S REPORT}

You will all have received copies of the 1987 Annual Report which describes the many activities of the College since last summer. I would like to mention some things which have occurred since the Report went to press in May.

The Court of Electors met last week and it was noted that 151 candidates, from a total of 283 , were successful in the Membership Examination. Both the Court and Council, over recent months, have been discussing ways of increasing the involvement of overseas members in the affairs of the College. It has been decided that in future one of the three Sub-Deans should have a special responsibility for overseas members and Council will be looking at a proposed remit for this Sub-Dean at its next meeting. I would be very interested to receive any suggestions which members may have about this.

I should like to draw to your attention some of the matters that Council discussed at its meeting last month. A Special Committee on Confidentiality has been set up under the Chairmanship of Dr Thomas Bewley, to report back to Council in 12 months time. The remit of the Committee is such that it will include:

(a) patients' access to their medical records, both computerised and manual, in the light of the Data Protection Act and the Access to Personal Files Act; (b) the use of shared confidential information with particular reference to the difficulties encountered by child and adolescent psychiatrists working in child guidance clinics with different employing authorities;

(c) confidentiality and research;

(d) conflicting advice on confidentiality from the Mental Health Act Commission, the GMC and other authorities.

The Chairman would be very interested to receive any examples of difficulties encountered by members in this sphere.

The Constitutional Sub-Committee presented a report to Council suggesting various amendments to the Bye-Laws. The amendments which were accepted will be circulated with papers for next year's Annual Meeting. Council had a detailed discussion about the criteria for the establishment of Sections and Groups. This has been remitted to the Executive and Finance Committee and I will report again on this at the Autumn Quarterly Meeting. Council agreed in principle to the formal establishment of Special Interest Groups (at present not recognised in the Constitution) and a note about this will be appearing in the Bulletin.

Council approved the proposals for the College to be associated with the publication of an additional journal Current Opinion in Psychiatry. This will be published by Gower Academic Press and represents a new concept for scanning, selecting and reviewing relevant world literature through a highly critical editorial system. It will appear bi-monthly and consist of 12 sections, each representing a major area of clinical or scientific interest. Each section will be covered once per annum. The journal will be offered to College members at an attractive discount.

The College is holding a meeting next week with the Mental Health Act Commission, MIND and other relevant organisations. The College will discuss its proposals to amend the Mental Health Act to include a Community Treatment Order, which will enable mentally ill patients to be given compulsory medical treatment in the community.

A notice of those members who generously contributed to the Research Unit Appeal appeared in the July Bulletin and a further list will appear early next year. Many members have responded to the President's letter in the Bulletin and the Annual Report, but further Covenant forms are available from the Registration Desk.

Building work will shortly start at No. 17 Belgrave Square. The kitchen will be enlarged during August; a new central heating system (which is long overdue) will be installed in the Autumn and the building of the additional storey will start in September. I hope that members visiting the College will not be too inconvenienced by thisinevitably it will cause some disruption. We expect that all works will be completed by the end of 1988 . 
I would like to announce the following election results: Professor A. C. P. Sims has been elected Dean; Drs T. H. Bewley, K. Day, J. Harris and S. Montgomery have been elected onto Council. Drs A. Gath, K. Schapira, S. Wolkind and Professors D. Goldberg and J. P. Watson have been elected onto the Court of Electors.

Other election results are as follows:

Dr D. Dickens: Chairman, Section for the Psychiatry of Mental Handicap; Dr C. Davies: Chairman, South Western Division; Dr R. J. W. Williams: Secretary, South Western Division; Dr R. G. McCreadie: Secretary, Scottish Division; Professor R. S. Bluglass: Chairman, Midlands Division; Dr R. Jones: Secretary, Midlands Division; Dr G. M. Petrie: Secretary, East Anglia Division; Dr S. A. Montgomery: Chairman, Chiltern \& Thames Valley Division; Dr P. D. Maddocks: Secretary, Chiltern \& Thames Valley Division.

The Autumn Quarterly Meeting will take place on 28-29 October 1987 in Kensington Town Hall, London.

Finally, I am sure that you all join me in thanking Professor R. McClelland, Dr W. A. G. MacCallum and their staff for organising such an enjoyable meeting in Belfast.

Election and introduction of Honorary Fellows

The following were unanimously welcomed to the Honorary Fellowship. Professor Nigel Walker was unable to attend and will be presented at a future meeting.

Professor George Brown (introduced by Dr J. L. T. Birley) Ladies and Gentlemen: At this exciting moment in my life, I would like you all to share another, connected with it, which I recall very vividly; it was a morning over 20 years ago when Dr George Brown and I set off from the Maudsley Hospital to the Hilger \& Watts factory in the Camberwell Road. This place made precision instruments and we hoped that its skilled craftsmen would prove to be co-operative subjects. This was the case, and we were soon launched on the exciting enterprise of trying to find out something about the rate and quality of life events in a normal population. For myself, this was a new and exhilarating experience, but for Dr Brown it was a logical step in a systematic exploration, which had been going on for some time, of the interconnections between a person's social and psychological world; a theme which he has developed so wonderfully over his career.

Sociologists have made immensely valuable contributions to our profession-as providers of new ideas, of new ways of looking at and describing social phenomena, and of criticism of our ways of thinking and practice. Professor Brown's work is in this great tradition but he also trained as an anthropologist, and his anthropological eye, with its attention to meaningful interactions, is very evident in his work. By a stroke of great good fortune for psychiatry he joined the MRC Social Psychiatry Unit, and began his research in the 1950s with John Wing on the effect of the institutional environment on people suffering from schizophrenia. It was soon evident that the so-called natural history of schizophrenia was profoundly affected by the environment and, if you like, a more systematic approach to the ecology of psychiatry began to be born. This work led to studies of social factors affecting the chances of patients being discharged, and of relapsing when they were discharged. This, in turn, led to a major methodological enterprise with Professor Michael Rutter on the study of a family interaction. Subsequently Professor Brown has been made a Fellow of the British Academy and Professor Rutter a Fellow of the Royal Society. It should be immensely heartening to all of us here that their marvellous achievements are based methodologically on good interviewing coupled with brilliant ideas. All sorts of new fields have been opened up, not with expensive technology and the latest laser beam, but by techniques which could be developed and used by anyone in this room.

Professor Brown continues to beckon us on, opening up new territory for us to follow. The work on schizophrenia and family and drug interaction has initiated many important studies, but his more recent work on depression, coupled with the findings of Leff \& Vaughn on factors affecting relapse in depression, have hardly begun to be developed in spite of their obvious significance for psychiatry and the increasing concern about the poor long term prognosis of depressive disorder.

There are, I believe, two hallmarks of Professor Brown's work. In the first place it is totally original. One senses the excitement of a new angle on things. Wilfred Trotter's statement that "There is no stronger antigen than a new idea", may explain the fact that the "Life Events and Schizophrenia' paper proved too antigenic for the British Journal of Psychiatry. Secondly, there is his interest in how people make sense of their world, how the meaning of an experience is related to its psychological effect. In pursuit of this theory, he has developed approaches which avoid the potentially circular arguments and logical pitfalls which abound in this field of work. Finally, Professor Brown has taken an interest, as an anthropologist, in psychiatrists and in institutions. He has worked in institutions, he understands psychiatrists and he has certainly influenced them. His remarkable paper, 'The Mental Hospital as an Institution', should, I believe, be read by every psychiatrist. He begins this paper with a quotation from a French writer, writing in 1803, "In proportion as habit makes us execute our activities with more ease and promptitude, it restrains our faculties and hinders them from being extended outside the same circle." When he considers how psychiatrists cope, or fail to cope, with the conceptual and emotional difficulties of caring for chronically disabled people, he concludes that "The medical profession must become much more aware of the dangers that stem from the very thing they most value, their training." As an ex-Dean, I can leave you with that intriguing paradoxical injunction. As a very new President, I must tell you that while some travel on a wing and a prayer, I believe my own trajectory has been fuelled by a Wing and a Brown. It is therefore with particular pleasure that I commend to you Professor George Brown as an Honorary Fellow of this College. 
Professor Alfred Meyer (introduced by Sir Martin Roth)

(Professor Meyer was represented by Dr N. Meyer)

The scientific contributions of Alfred Meyer to neuropathological and neurobiological science extend over a period of more than 60 years. The work on which he embarked after his arrival in England in the 1930s formed an important starting point of the renaissance of neuropathological investigation in psychiatry that has slowly come to fruition in the course of the last half century.

After service in the Army during the First World War he resumed his medical studies which had been interrupted in 1914. He graduated in the University of Bonn and in 1921 joined the University Clinic for Nervous and Mental Diseases, then under the direction of Alex Westphal. His early contributions were stimulated by the publications of Kretschmer. The enquiries he conducted in collaboration with Sioli into the relationships between body-build and character confirmed a number of Kretschmer's findings. During this clinical phase of his career in the early 1920s he also published observations on the neurological sequelae of encephalitis lethargica which included one of three simultaneous original descriptions of the oculogyric crisis.

It was with deep regret that he gave up clinical psychiatry to take up a vacancy in the Academic Department as a neuropathologist. In 1926 he came under the influence of the famous German neuropathologist Spielmeyer, and embarked on his important studies into the effects of carbon monoxide on the brain of experimental animals. The selective vulnerability of cortical and sub-cortical structures to the influence of hypoxia made a deep impression on Meyer and he was to return to this subject in a number of his later investigations.

The establishment of Hitler's Nazi regime in Germany forced him to emigrate to Great Britain. His arrival at the Maudsley Hospital, where he was warmly received by Edward Mapother and F. L. Golla, coincided with that of W. Mayer-Gross who had been an Associate Professor at Heidelberg and Erich Guttmann who had taught at the University of Breslau.

The progress of British psychiatry and the leading position it achieved during the first 25 years after the end of the Second World War probably owed more to the work of these three remarkable men and to the contributions of others such as Erwin Stengel and Rudolf Klein than to any other single influence. They brought with them the stringent discipline of German phenomenological analysis of clinical disorders and an empirical approach towards the scientific problems posed by mental illness. When account is taken of the fact that they had not only been uprooted, humiliated and dispossessed but had to establish themselves professionally and socially in a foreign country, and acquire a new language, the productivity of Meyer and of his two compatriots at the Maudsley was astonishing.

Reading again the papers which began to flow in abundance from their pen in the mid-thirties to fill the
English and international journals, one is struck by the lucidity, vigour and freshness with which they wrote and the felicity with which they expressed themselves about complex and, in the case of the clinical problems, convoluted issues. It has to be admitted that some of the literary distinction had stemmed from the generous help given by Eliot Slater who had come under the influence of European psychiatry in Munich where he had trained in psychiatric genetics and met Mayer-Gross. But the concepts and the clarity were the authors' own. The clinical and neurobiological enquiries of this group made a particularly powerful impression upon Eliot Slater, perhaps the most scientifically imaginative and gifted British psychiatrist of his generation.

The range of Meyer's creative curiosity during this period is reflected in the diversity of the problems he tackled, the elegance of his methods and his painstaking scholarship. Familial Schilder's disease, tuberose sclerosis, the interpretation of circulatory disturbances in the brain, and the histology of epilepsy were all the subject of papers by Meyer and his co-workers in this period. The Wernicke syndrome had been previously studied but the title of Meyer's paper posed a new question in the words "with special reference to manic syndromes associated with hypothalamic lesions". A number of the papers were devoted to the neuropathology of different forms of mental sub-normality. And there was a classical paper on the histological changes in the brain of patients with Down's Syndrome, a subject which has become the focus of recent scientific attention owing to certain pathological features that it has in common with Alzheimer's disease.

A number of these studies were developed and completed against a background of the turmoil, threat and anxiety of the Second World War when our fate and future were often to hang in the balance. In 1949 he was elected to the Chair of Neuropathology at the Institute of Psychiatry. The post-war period was dominated by Meyer's important neuropathological contributions to the precise extent and characters of the observed changes in the cerebrum that followed prefrontal leucotomy; they shed new light on the relationship between the clinical changes and the course of illness following operation on the one hand and the lesions created in the brain on the other. These were examined in intricate anatomical detail and defined with the aid of quantitative measures in the patients who had died after a period and had come to post-mortem. Quantitative methods had been previously employed in neuropathology but the knowledge of cerebral anatomy and function, biological insight and the rigorous and elegant statistical analysis undertaken in collaboration with Eliot Slater were probably unique. The results established a clear correlation between the extent and localisation of the lesions and the clinical effects achieved in the mental disorders that treatment was intended to relieve. The findings were incorporated in the Ramsay Henderson Lectures Meyer delivered in Edinburgh in 1953 and the monograph he published with Elizabeth Beck in the following year. 
Many of Meyer's collaborators in this period were to achieve distinction in British psychiatry including Tennent, Pilkington, Earl, McKeith, T. B. Jones, Nightingale and Denis Leigh. In the studies of pre-frontal leucotomy Turner McLardy and Elizabeth Beck made important contributions. Beck's work role in the recent development of knowledge of the aetiology of Creutzfeldt-Jakob disease should be better known than it is.

Meyer's name will also go down in the history of neurobiology for his illuminating studies of the pathology of temporal lobe epilepsy in collaboration with Murray Falconer, Desmond Pond and J. B. Cavanagh.

He was working here along a frontier at which the signals that emanated from cerebral physiological activity are integrated and decoded to be channelled into the emotional and cognitive aspects of man's mental life. The temporal lobes and limbic system have come to be recognised in recent decades as being involved in the pathophysiology and causation of the syndromes of depersonalisation, panic disorder, schizophrenia, memory deficit and Alzheimer's disease as well as the protean manifestations of temporal lobe epilepsy. When we have come to understand the nature of the functional cerebral system held in common by this diversity of disorders, an enormous stride will have been taken towards the psychiatry of the future.

The length of this list of names plays tribute to Meyer's generosity of spirit and his capacity to ignite in others a desire or a passion for the expansion of knowledge that might otherwise have remained latent or proved stillborn.

In his retirement Professor Meyer has continued in indefatigable fashion with his scholarly enquiries which have found expression in papers on the contributions of Thomas Willis, Marcello Malpighi and Karl Burdach, critical reviews of the frontal lobe syndrome, the aphasias and the concept of a sensorimotor cortes. His monograph Historical Aspects of Cerebral Anatomy was published by Oxford University Press in 1979. This period has also seen the fruits of his collaboration with Eliot Slater in pathographic studies of the great musicians which have illuminated the psychopathology of Schumann and a number of other musicians together with some distinctive features of their personalities and the ebb and flow of their creative life. Meyer's role was of critical importance. Those who knew him before he was afflicted with deafness will remember the delicacy and depth of interpretation at the keyboard of 19 th century music in particular.

In his 92nd year Alfred Meyer remains with us and the inspiration in his life in the last $\mathbf{4 0}$ years of his life the Nina half of Ninafred, as they have come to be known, has honoured us with her presence today. The force of his example in creative scientific work, intellectual distinction and scholarship coupled with generosity of spirit, a rare personal integrity and dedication have made contributions of lasting importance for psychiatry and neurological science in this country and the world at large. His influence will continue in years to come. Mr President I present to you the name of Alfred Meyer as worthy of the highest honour we can bestow, the Honorary Fellowship of our Royal College.
Dr Michael Pare (introduced by $\operatorname{Dr}$ T. H. Bewley)

Dr Michael Pare was born in 1925 in Bolton where his father was a general practitioner. He left Marlborough College to study medicine at Cambridge University and the Middlesex Hospital Medical School, qualifying in 1948. He practised medicine, becoming a member of the Royal College of Physicians of London in 1950. Then, as a conscript in the army and a junior specialist in medicine in the RAMC, he became interested in research and worked with Merton Sandler, later Professor Merton Sandler. He next moved to the Maudsley Hospital to train as a psychiatrist and again co-operated with Merton Sandler, looking at serotonin abnormalities in phenylketonuria and other types of mental subnormality. This interest in serotonin led to a lifelong interest in depressive illness and monoamine oxidase inhibitors. This has resulted in a series of papers on the effects of monoamine oxidase inhibitors on brain amines and different isoenzymes of MAB in human (postmortem) brains and has included papers on postmortem studies of suicides. In 1959 he was awarded a US Public Health Services Travelling Fellowship on the recommendation of the MRC and worked at the National Institute for Health in Washington with Professor Seymour Kety. At this time Julius Axelrod and his laboratory were doing their Nobel Prize work and Michael Pare published a couple of papers with Axelrod on melatonin.

He then returned to England in 1960 to become a consultant at the Department of Psychological Medicine, St Bartholomew's Hospital. During the whole of his professional life he has continued to be interested in the biological and scientific basis of mental illness and has continued his researches and written widely about these aspects of psychiatry. He has most recently been interested in clinical methods of decreasing the risk of hypertensive attacks in patients taking monoamine oxidase inhibitors. He has been a member of many organisations interested in brain research and psychopharmacology, having been British representative on the Committee for Neuropsychopharmacology of the World Psychiatric Association and he became Secretary of its Section of Pharmacopsychiatry.

So far I have given a mundane list of some of Dr Pare's posts, research interests and achievements, but $I$ have said nothing of Dr Pare himself. I now propose to do so slightly indirectly. The author Anthony Daniels is a doctor who, having worked for 12 years in Africa and the South Pacific, returned to England to qualify as a psychiatrist. He spent three years in training at St Bartholomew's Hospital. He wrote a book Fool or Physician and in this there were some thinly disguised portraits of psychiatrists in his descriptions of the staff of an anonymous East End psychiatric unit. The consultant with whom Anthony Daniels had most to do was a Dr Partridge and I will quote his description of Dr Partridge:

“... He was a man of imperturbable wisdom, who had also made contributions to neurochemical science. He was the very antithesis of the psychiatrist as popularly conceived; neatly dressed, well-ordered and of self-evident sanity. He was capable of inspiring instant confidence in 
patients, who I am certain would unhesitatingly confide in him their innermost (and usually disreputable) secrets, knowing that they were stones that went to the bottom of a very deep pond. He achieved an equanimity in the face of human folly that I knew I should never be able to emulate."

I believe that this is a rare sighting of a Partridge in a Pare tree. Dr Daniels' description of a man of imperturbable wisdom reminds me of the College's motto "Let Wisdom Guide" and I would like to turn now to Dr Pare's connections with this College.

Dr Pare has been involved with the College in many different ways since its inception and had previously been involved with its predecessor, the RMPA. He was Secretary, and later Chairman, of the Programmes and Meetings Committee and did much to improve the scientific quality of Quarterly and Annual General Meetings and the standards of presentation at them. He followed this by being the Treasurer for seven years, from 1979 to 1986. Treasurers fall into two groups: the first are manic and spend as much money as they can; the second are depressed and hoard all they can, spending nothing. Dr Pare appears to have been able to both increase the value of the College's funds and extend its building without cutting back on normal expenditure. This I believe must be credited to his imperturbable temperament which has been mentioned earlier. Wisdom and probity are the qualities required of a Treasurer rather than fiscal ability or numeracy and Dr Pare had the necessary qualities in abundance. Dr Pare currently has the oversight of the College's Public Education Department.

The College Charter gives more than one reason for awarding an Honorary Fellowship. Firstly, for eminence in psychiatry or having rendered distinguished service in relation to the study, prevention and treatment of mental illness and also where someone has rendered notable service to the College. Dr Pare is very well qualified for the Honorary Fellowship for all of these reasons.

Professor Erik Strömgren (introduced by Professor E.S. Paykel)

Professor Strömgren is the doyen of Danish psychiatrists.
His father was Professor of Astronomy in Copenhagen (a post more recently held by his brother) and he was born in 1909 in the Royal Observatory, a beginning which may have contributed to his vision and wide perspective. He graduated from the University of Copenhagen Medical School and studied in Munich in the great research institute founded by Kraepelin.

From 1945 to 1980 he was Professor of Psychiatry in the University of Aarhus and Medical Superintendent of the Psychiatric Hospital in Risskov, in the grounds of which he gradually established a comprehensive and internationally famous research institute. He made major contributions to psychiatric genetics and to the use of stringent scientific methods in clinical psychiatric research. Genetics led to an interest in populations and to epidemiological studies on the islands of Bornholm and Samso on a grand scale.

He became Editor of the Acta Psychiatrica Scandinavica in 1953 and guided that excellent journal through some of its most distinguished years. His mastery of epidemiological data, his extensive knowledge of clinical psychiatry and his objective attitude to policy made him the main architect of the Mental Health Services in Denmark. He was Chairman of the World Psychiatric Association Section on Nomenclature and Classification from 1972-77. He has been widely influential in the development of ICD10 and prominent in many other activities in the World Health Organization. His wife, Lizzy Sand Strömgren, is a distinguished psychiatrist in her own right. Professor Strömgren is a man of wide culture, integrity and strength of purpose and has been honoured in all parts of the world for his contributions. He is an honorary member of psychiatric bodies in Denmark, Sweden and Germany, has been a recipient of the Ernst Carlsen Honorary Prize, the Norwegian Anders Jahre Prize, the Kraepelin Gold Medal, the Julius Wagner von Jauregg Medal. He was the Maudsley Lecturer of this College in 1985.

It is a privilege and a pleasure to present Professor Strömgren to you now for award of the Honorary Fellowship of our College.

\section{Postgraduate psychiatry training at Keele}

The Division of Psychiatry, Department of Postgraduate Medicine, is arranging the following postgraduate training programmes for the next academic year:

(1) Academic Psychiatry Foundation Course (Course Organiser: Dr K. Barrett). This course is designed with the requirements for MRCPsych Part I in mind.

(2) The Two Year Academic Course. This will assist in preparing trainees for MRCPsych Part II but will also assist trainees who are considering registering for the MSc Degree by thesis.
Advanced courses in puerperal mental illness, international and transcultural psychiatry are planned during the forthcoming academic year.

Further particulars and registration forms can be obtained from Mrs Norma Steele, Department of Postgraduate Medicine, University of Keele, Thornburrow Drive, Hartshill, Stoke on Trent ST4 7QB (telephone 0782 49144, Ext 4047). 